\title{
Testicular epidermoid cyst - Ultrasound and MR typical findings with macroscopy correlation
}

\author{
L. Pires-Gonçalves, C. Silva, M. Teixeira, S. Costa-Dias, V. Sousa-Mendes
}

Department of Imagiology (LPG, SCD, VSM), Department of Urology (CS) and Department of Pathology (MT) of Hospital de Braga, of Hospital de Braga, Braga/Portugal

A 16-year-old male presented with a painless right testicular mass, known for the past 2 years and that had recently increased in size. Physical examination confirmed a hard testicular mass and no evidence of lymphadenopathy or of gynecomastia. Laboratory results, including tumor markers, were normal.
Ultrasound (US) revealed a solid mass in the upper pole of the right testis that was well circumscribed, avascular, and displayed the onionskin appearance suggestive of testicular epidermoid cyst $(1,2)$ (Figure-1).

Magnetic resonance (MR) confirmed the well-circumscribed intra-testicular mass with a
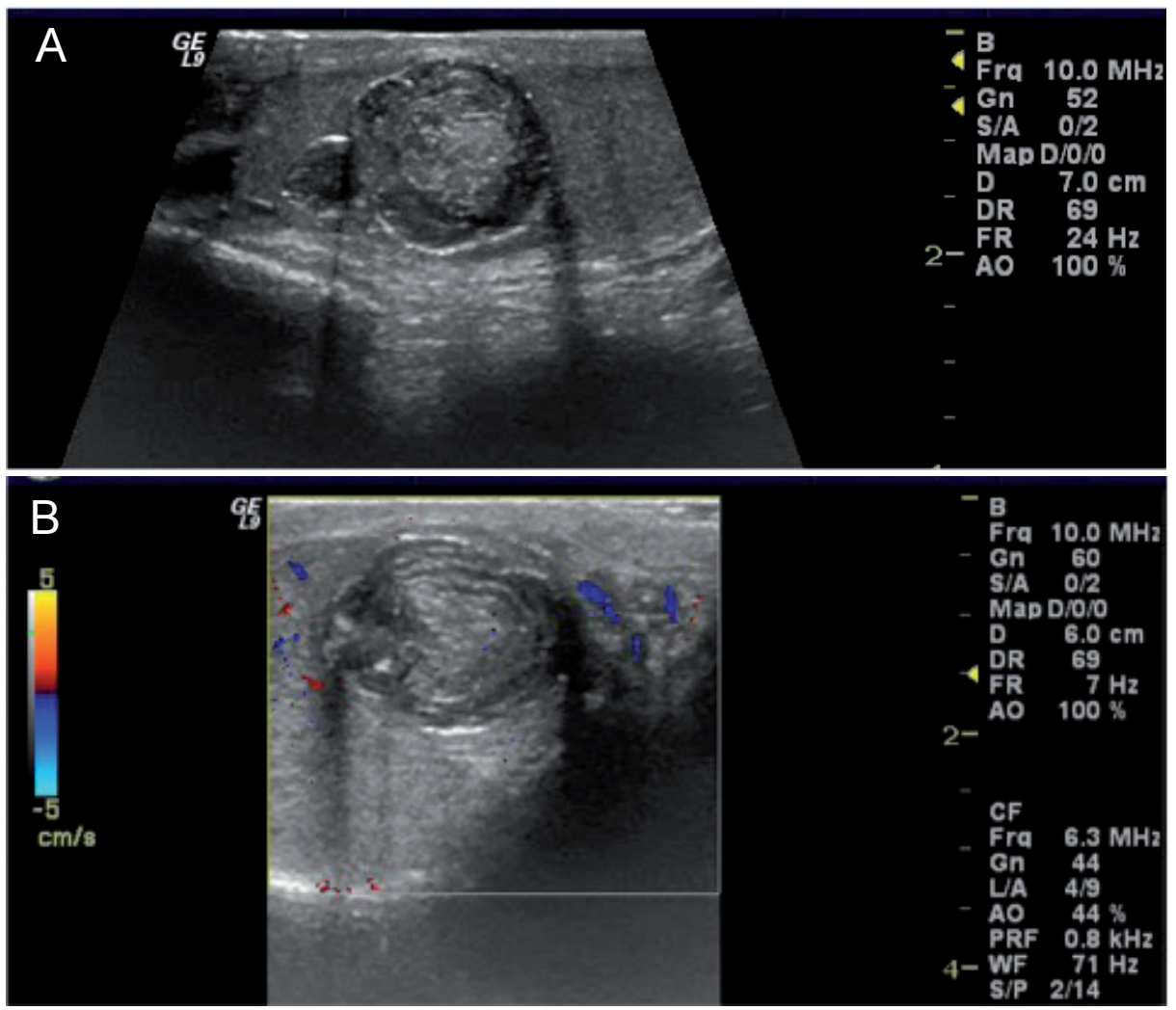

Figure 1 - a. Longitudinal US image of the right testis show a bilobulated mass in the upper medial aspect of the testis. The mass had sharp margins, composed of a central echogenic area and of alternating hyperechogenic and hypoechogenic rings in the periphery (onionskin sign), measuring $2.4 \times 1.7 \times 1.7 \mathrm{~cm}$. b. Longitudinal Doppler-US image of the right testis demonstrates the absence of vascularization of the mass. 
central area hyperintense on T1 and hypointense on $\mathrm{T} 2$ and a peripheral area isointense on $\mathrm{T} 1$ and hyperintense on T2, displaying the target or bull's eye appearance, typical of testicular epidermoid cyst $(1,2)$ (Figure-2). The remaining testicular parenchyma was unremarkable.

Surgical enucleation of the right testicular mass was performed (3). The pathological analysis of the surgical specimen confirmed the clinical and radiological proposed diagnosis

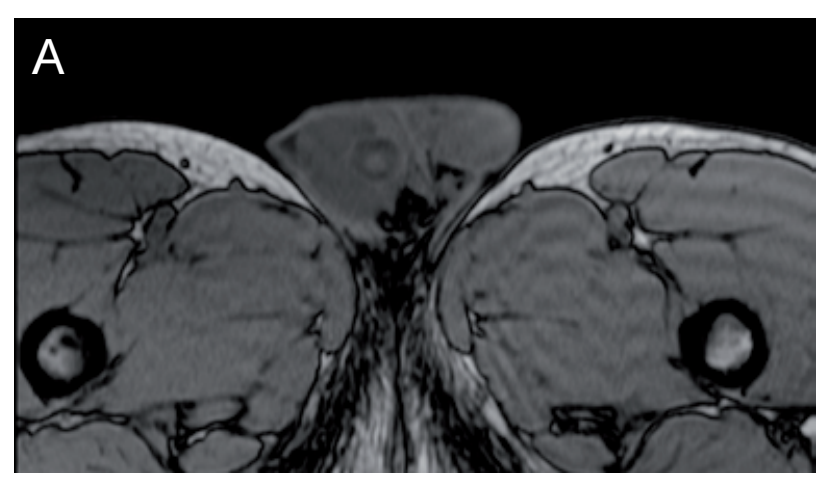

$(1,2,4)$ (Figure-3). The postoperative follow-up was uneventful.

The case presented demonstrates the clinical, ultrasound, and MR findings diagnostic of testicular epidermoid cyst with macroscopy correlation. The recognition of the typical imaging findings of testicular epidermoid cyst can suggest the pre-operative diagnosis of this rare benign tumor thus allowing to considered organ-preserving surgery and its associated psychological and cosmetic benefits.

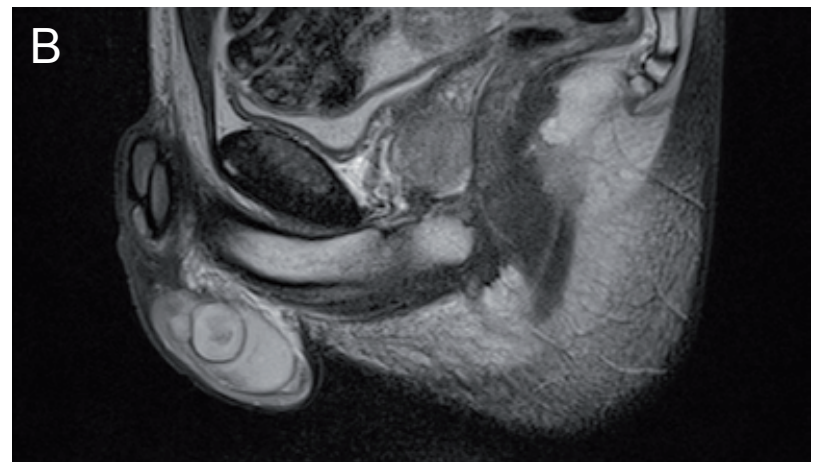

Figure 2 - a. Axial T2-weigthed image confirms the well-circumscribed mass in the upper medial pole of the right testis. The mass has a central slightly hyperintense center and an isointense periphery. b. Sagittal T2-weigthed image confirms the well-circumscribed mass in the upper medial pole of the right testis. The mass had a central slightly hypointense center and a hyperintense periphery.

\section{REFERENCES}

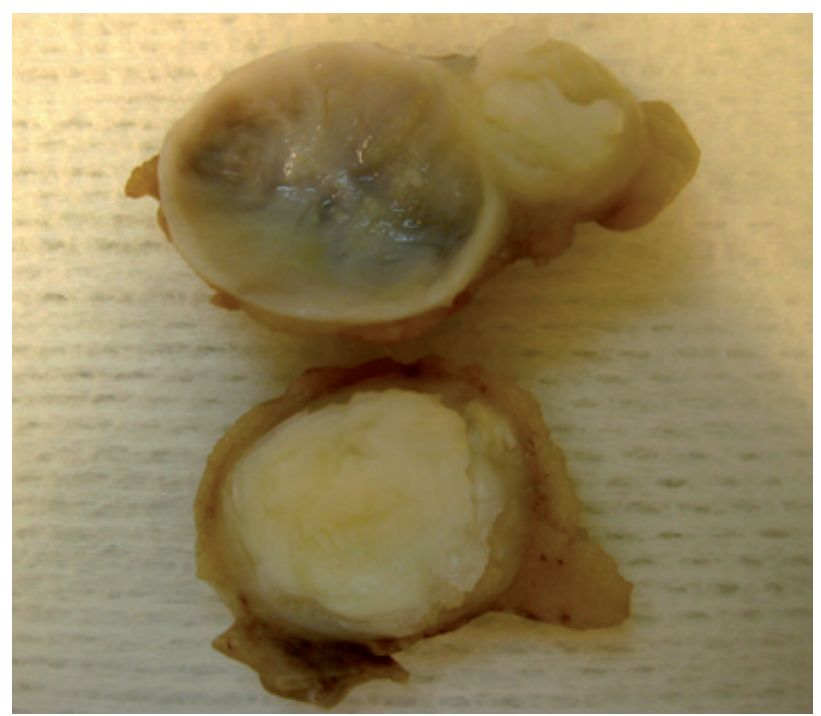

Figure 3 - Photograph of the sectioned surgical specimen shows a bilobulated mass with a fibrous capsule that was composed of a laminated white-yellow paste like material, typical of keratin.
1. Loya AG, Said JW, Grant EG: Epidermoid cyst of the testis: radiologic-pathologic correlation. Radiographics. 2004; 24(Suppl 1): S243-6.

2. Cho JH, Chang JC, Park BH, Lee JG, Son CH: Sonographic and MR imaging findings of testicular epidermoid cysts. AJR Am J Roentgenol. 2002; 178: 743-8.

3. Heidenreich A, Engelmann UH, Vietsch HV, Derschum W: Organ preserving surgery in testicular epidermoid cysts. J Urol. 1995; 153: 1147-50.

4. Dieckmann KP, Loy V: Epidermoid cyst of the testis: a review of clinical and histogenetic considerations. Br J Urol. 1994; 73: 436-41.

\section{Correspondence address:}

Dr. Lígia Pires-Gonçalves

Department of Imagiology, Hospital de Braga

Largo Carlos Amarante, 2242

Braga, 4701-965, Portugal

Fax: + 351253 613-334

E-mail: 1.f.p.goncalves@gmail.com 


\section{UROLOGICAL SURVEY}

Athanase Billis

State University of Campinas

Campinas, SP, Brazil

Andreas Böhle

Helios Agnes Karll Hospital

Bad Schwartau, Germany

Sean P. Elliott

University of Minnesota

Minneapolis, MN, USA

Fernando J. Kim

Univ Colorado Health Sci Ctr

Denver, Colorado, USA
Ricardo Miyaoka

State University of Campinas

Campinas, SP, Brazil

Manoj Monga

University of Minnesota

Edina, MN, USA

\section{Adilson Prando}

Vera Cruz Hospital

Campinas, SP, Brazil

Leonardo O. Reis

State University of Campinas

Campinas, SP, Brazil

M. Chad Wallis

University of Utah

Salt Lake City, Utah, USA 